\title{
The Moderating Effect of Team Orientation Over the Relationship Between TMT Strategic Decision Speed and Firm Performance
}

\author{
Claudia Ramos-Garza, Olivia Villalba-Moreno \\ EGADE Business School Monterrey, Tecnologico de Monterrey, Mexico \\ Leticia Ramos-Garza \\ School of Business, Social Science and Humanities, Tecnológico de Monterrey, Mexico
}

\begin{abstract}
Due to the fast changing competitive environment faced by organizations, companies are forced to find ways to quickly adapt to technological innovations, changing demands of customers, and strategic actions taken by competitors. The purpose of the paper is to further the relationship between top management team (TMT) strategic decision speed and firm performance, considering the team processes when making strategic decisions in the face of complex environments. Measures of TMT strategic decision speed, firm performance, team orientation, and environmental complexity were collected from 29 top management teams of Mexican companies, which represented a total of 118 questionnaires. Pearson correlations among the variables and moderated regression analyses were performed, to test the hypotheses included in the study. Results show a positive relation between environmental complexity and TMT strategic decision speed and between team orientation and speed. Furthermore, results show that there is a positive relation between TMT strategic decision speed and firm performance in the presence of team orientation. In other words, team orientation moderates the relationship between TMT strategic speed and firm performance. Among the implications for managers is that they must ensure effective team processes (e.g., building consensus, active participation, and trust among team members) when making strategic decisions in order for the firm to perform better.
\end{abstract}

Keywords: strategic decision speed, team orientation, TMT, firm performance, complex environments

\section{Introduction}

Due to the fast changing competitive environment faced by organizations, companies are forced to find ways to quickly adapt to technological innovations, changing demands of customers and strategic actions taken by competitors. Strategic decision process theory proposes that decision makers' cognitions are motivated and constrained by their business environments, organizational structures, resources, as well as their personal experiences and perceptions (Baum \& Wally, 2003; Zehir \& Ozsahin, 2008).

Claudia Ramos-Garza, Ph.D. , Associate Professor, Management Department, EGADE Business School Monterrey. Olivia Villalba-Moreno, Ph.D., Full Professor, Management Department, EGADE Business School Monterrey. Leticia Ramos-Garza, Ph.D., Full Professor, School of Business, Social Science and Humanities, Campus Monterrey..

Correspondence concerning this article should be addressed to Claudia Ramos-Garza, Tecnológico de Monterrey, Ave. Fundadores y Rufino Tamayo 66269, San Pedro Garza García, N.L., México. E-mail: cramos@itesm.mx. 
Some (e.g., Judge \& Miller, 1991) consider that making fast strategic decisions has a positive impact on performance and can even be a source of competitive advantage (e.g., Jones, 1993). So, the speed of strategic decisions-making might be influenced by the individuals making the decisions (in this study, the members of the top management team), their team processes and the environment faced by the company.

The purpose of the paper is to further the relationship between top management team (TMT) strategic decision speed and firm performance, considering their team processes when making strategic decisions in the face of complex environments.

\section{Theory and Hypotheses}

The proposed model showing the relationships among the variables included in the study (TMT strategic decision speed, firm performance, environmental complexity, and team orientation) is included in Figure 1.

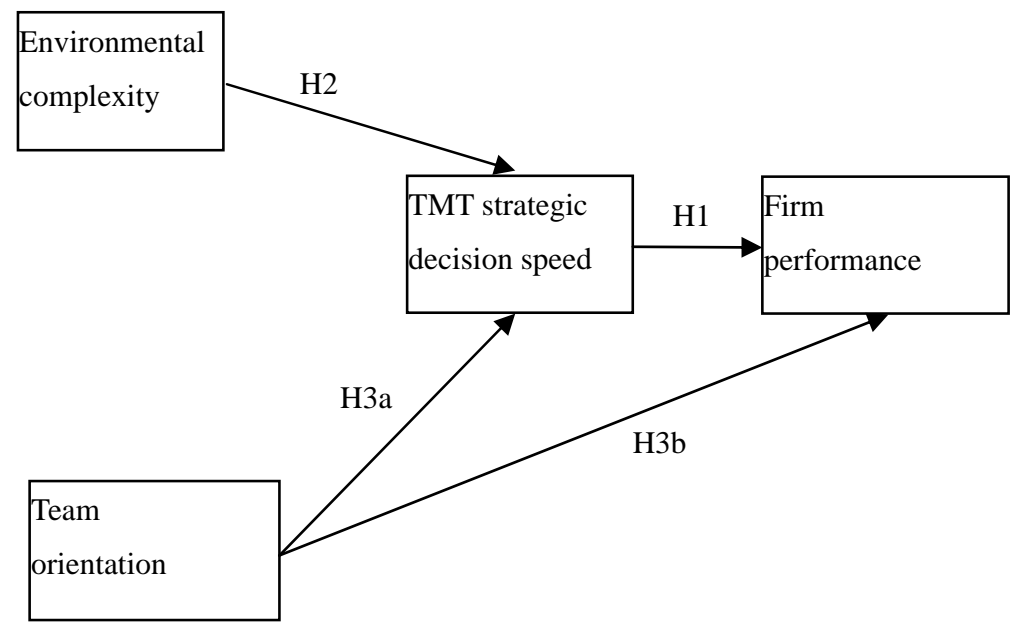

Figure 1. Proposed model: Relationships between TMT strategic decision speed, team orientation, environmental complexity, and firm performance.

\section{TMT Strategic Decision Speed and Firm Performance}

TMT strategic decision speed is defined as how fast TMT members make strategic decisions. Some researchers argue that making fast strategic decisions may lead to better performance (Baum \& Wally, 2003; Bourgeois \& Eisenhardt, 1988; Eisenhardt, 1989; Judge \& Miller, 1991) and consider it a source of competitive advantage (Jones, 1993). For example, Eisenhardt (1989) observed that in high velocity environments, the fastest decision makers had the best profitability and sales. Also, Judge and Miller (1991) found a positive association between speed and performance in the biotechnology industry. In the same line, Baum and Wally (2003) found that strategic decision speed predicts subsequent firm performance (e.g., profit and growth). Finally, Bourgeois and Eisenhardt (1988) analyzed four cases in the computer industry and found that major decisions should be made carefully and quickly, should have a powerful TMT, should seek risk and innovation, and should execute safely, incremental implementation in the face of high velocity environments. Considering this information, we propose the following hypothesis.

H1: Faster strategic decisions are positively related to firm performance.

\section{Environmental Complexity}

Environmental complexity refers to the heterogeneity and range of environmental activities that are relevant to an organization's operations (Child, 1972). It includes the number of elements and their 
interconnectedness (Dess \& Beard, 1984).

Some researchers (e.g., Eisenhardt, 1989; Judge \& Miller, 1991) have found a positive relationship between speed and firm performance when firms face high velocity environments. According to Tushman and Romanelli (1986), an adequate fit of external opportunity, company strategy, and internal structure is a hallmark of successful companies. They further point out that the real test of executive leadership is maintaining this alignment in the face of changing competitive conditions. The TMT must recognize external threats and opportunities and take the necessary steps to deal with them rapidly. Inaction in the face of environmental shifts is a certain recipe for failure (Tushman \& Romanelli, 1986). If companies want to be successful, decision makers must not establish a static state of mind but must constantly search for new ways of doing business. So, it appears that complex environments force companies to make quicker strategic decisions in order to be successful. Considering this information, we propose the following hypothesis.

H2: Environmental complexity is positively related to strategic decision speed.

\section{Team Orientation}

Team orientation is the extent to which top managers perceive they are working together as a team (Isabella \& Waddock, 1994). To capture the dynamic of a team, they suggest ten team processes, among them: building consensus, trusting each others' judgments, communicating freely, agreeing on final decisions, and allowing participation.

Zehir and Ozsahin (2008) found a linkage between participation and strategic decision making speed. Specifically, they found that extensive participation accelerates the pace of decision making. It appears that it is not enough to be fast, you need to make quality decisions, and for that you need to have effective team processes (strong team orientation).

Furthermore, Camelo-Ordaz, Hernandez-Lara and Valle-Cabrera (2005) suggested that the processes that occur within the team might have a significant impact on performance. In this regard, Isabella and Waddock (1994) argued that communication, trust, and participation lead to increased information sharing and processing and that these processes might enhance working together as a team and hence can have a positive impact on organizational results. They found that when perceptions of strong team orientation increased, so did the certainty about the decisions the TMT made. They also found a significant and positive relationship between certainty and performance. Considering this information, we propose the following hypotheses:

H3a: Team orientation is positively related to TMT strategic decision speed.

H3b: Team orientation is positively related to firm performance.

\section{Methodology}

\section{Sample}

The unit of analysis was the team level. TMTs of 29 medium and large manufacturing companies located in Mexico were included in the sample. The companies' CEOs were asked to select as participants in the study, the members of his/her TMT, considering those who actively participate in the strategic decision making process of the firm. One hundred and eighteen usable questionnaires were collected.

\section{Measures}

TMT strategic decision speed is defined as how fast TMT members make strategic decisions. To capture TMT strategic consensus, Knight, Pearce, Smith, Olian, Sims, Smith and Flood (1999) captured strategic 
consensus using a broad and informed strategic management literature, including Eisenhardts' (1989) notion of speed of the firm's strategic behavior. Strategic decision speed was measured using the items considered in Knight's scale in regard to speed, seven 5-point-Likert-type scales were used. The measure captures how fast the firm can: develop new products compared to its competitors, respond to costumers' needs, respond to competitors' actions, seize opportunities, be proactive and a pioneer. The reliability of the strategic decision speed measure was $\alpha=0.819$.

Firm performance refers to how well the organization is doing with regard to efficiency and growth indicators. It was assessed using efficiency (return on investment: ROI) and growth measurements (sales). Following Bowman and Ambrosini (1997), it was measured using one 5-point-Likert-type scale measuring for efficiency (ROI) and one 5-point-Likert-type scale for sales growth. The CEO was asked to rate their firm's performance (ROI and sales growth) relatively to other firms in their industry.

Environmental complexity refers to the heterogeneity and range of environmental activities that are relevant to an organization's operations (Child, 1972). It includes the number of elements and their interconnectedness (Dess \& Beard, 1984). It was measured using four 5-point-Likert-type scales used by Papadakis, Lioukas and Chambers (1998) originally used by Miller and Friesen (1983) and five 5-point-Likert-type scales used by Calori, Johnson and Sarnin (1994). The instrument measured significant differences between the new products/services offered (Papadakis et al., 1998), in relation to: changing customer's buying habits, the nature of the competition, market dynamism and market uncertainty; and it also assess the scope of the company (Calori et al., 1994), in relation to: the scope of the company (including products, suppliers, clients, industry segments and geographic scope). The reliability of the environmental complexity measure was $\alpha=0.743$.

Team orientation is the extent to which top managers perceive they are working together as a team (Isabella \& Waddock, 1994). To capture the dynamics of a team we used Isabella and Waddock's team orientation measure. Team orientation includes the following process: making decisions as a team, getting along with each other, building consensus, trusting each others' judgments, communicating freely, listening to opinions, tolerating disagreement, delegating authority, agreeing on final decisions, and allowing participation. The reliability of the team orientation measure was $\alpha=0.925$.

\section{Analytic Approach}

Pearson correlations among the variables and moderated regression analyses were performed to test the relationship between TMT strategic decision speed and firm performance.

\section{Results}

The means, standard deviations, and correlations are presented in Table 1. First, for H1, we proposed that faster strategic decisions are positively related to firm performance. We found no direct relation between speed and performance neither for ROI ( $r=0.33, p=0.08)$ or sales growth $(r=0.22, p=0.26)$. However, using moderated regression analyses, we further analyze the relationship between TMT strategic decision speed and firm performance considering the possible moderating effects that team orientation might have. Interestingly, we found a moderating effect for team orientation $(r=0.40, p=0.03)$ when performance was measured using ROI. Results show that there is a positive relation between speed and performance in the presence of strong team orientation. Thus, there was some support for H1.

Second, for H2, we proposed that environmental complexity is positively related to strategic decision speed. 
We found a positive relation ( $r=0.40, p=0.03$ ) between environmental complexity and TMT strategic decision speed. Thus, finding support for $\mathrm{H} 2$.

Finally, for H3, we proposed that team orientation is positively related to: (1) TMT strategic decision speed; and (2) firm performance. We found a positive relation $(r=0.52, p=0.004)$ between team orientation and TMT strategic decision speed. A direct relation between team orientation and firm performance using ROI $(r=0.36, p$ $=0.055)$ or sales growth $(r=0.20, p=0.29)$ was not found. Thus, finding support only for H3a.

Table 1

Means, Standard Deviations and Correlations $(N=29)$

\begin{tabular}{|c|c|c|c|c|c|c|c|}
\hline Scales & Means & s.d. & 1 & 2 & 3 & 4 & 5 \\
\hline 1. TMT strategic decision speed & 3.64 & 0.47 & - & & & & \\
\hline 2. Environmental complexity & 3.32 & 0.62 & $0.400^{*}$ & - & & & \\
\hline 3. Team orientation & 4.03 & 0.37 & $0.524^{* *}$ & 0.059 & - & & \\
\hline 4. Performance (ROI) & 3.69 & 1.00 & 0.328 & -0.013 & 0.359 & - & \\
\hline 5. Performance (sales growth) & 4.00 & 1.00 & 0.216 & 0.123 & 0.204 & $0.534^{* *}$ & - \\
\hline
\end{tabular}

Notes. ${ }^{*} p<0.05 ;{ }^{* *} p<0.01$.

\section{Conclusions: Implications for Managers}

The purpose of the study was to contribute to the literature of strategic management, concerning factors that affect TMT strategic decision speed and its relationship with firm performance. We found a positive relation between environmental complexity and TMT strategic decision speed and between team orientation and TMT strategic decision speed. Furthermore, we found a positive relation between TMT strategic decision speed and firm performance in the presence of team orientation. So, interestingly team orientation moderates the relationship between TMT strategic decision speed and firm performance when measured by ROI.

These results have important implications for managers. Team orientation includes team processes that managers should enhance in order to quickly respond to environmental changes. Team processes such as making decisions as a team, building consensus, encouraging member participation, allowing open communication, increasing trust among team members, agreeing of final decisions, among others. So, managers must ensure effective team processes (e.g., building consensus and active participation) when making strategic decisions.

No doubt, this topic will continue to be of interest for both academics and practitioners, due to the fact that TMTs have the responsibility for crucial strategic decisions that impact the future and survival of organizations.

\section{References}

Baum, J. R., \& Wally, S. (2003). Strategic decision speed and firm performance. Strategic Management Journal, 24, 1107-1129. Bourgeois III, L. J., \& Eisenhardt, K. M. (1988). Strategic decision processes in high velocity environments: Four cases in the microcomputer industry. Management Science, 34(17), 816-835.

Bowman, C., \& Ambrosini, V. (1997). Perceptions of strategic priorities, consensus and firm performance. Journal of Management Studies, 34(2), 241-258.

Calori, R., Johnson, G., \& Sarnin, P. (1994). CEOs' cognitive maps and the scope of the organization. Strategic Management Journal, 15(6), 437-457.

Camelo-Ordaz, C., Hernandez-Lara, A. B., \& Valle-Cabrera, R. (2005). The relationship between top management teams and innovative capacity in companies. Journal of Management Development, 21(8), 683-705.

Child, J. (1972). Organizational structure, environment and performance: The role of strategic choice. Sociology, 6(6), 1-22.

Dess, G. G., \& Beard, D. W. (1984). Dimensions of organizational task environments. Administrative Science Quarterly, 29(1), 52-73. 
Eisenhardt, K. M. (1989). Making fast strategic decisions in high-velocity environments. Academy of Management Journal, 32(3), 543-576.

Isabella L. A., \& Waddock S. A. (1994). Top management team certainty: Environmental assessments, teamwork, and performance implications. Journal of Management, 20, 835-858.

Jones, J. W. (1993). High speed management: Time-based strategies for managers and organizations. Jossey-Bass: San Francisco, CA.

Judge, W. Q., \& Miller, A. (1991). Antecedents and outcomes of decision speed in different environmental contexts. Academy of Management Journal, 34(2), 449-463.

Knight, D., Pearce, C. L., Smith, K. G., Olian, J. D., Sims, H. P., Smith, K. A., \& Flood, P. (1999). Top management team diversity, group process, and strategic consensus. Strategic Management Journal, 20, 445-465.

Miller, D., \& Friesen, P. H. (1983). Strategy-making and environment: The third link. Strategic Management Journal, 4(3), 221-235.

Papadakis, V. M., Lioukas, S., \& Chambers, D. (1998). Strategic decision-making processes: The role of management and context. Strategic Management Journal, 19, 115-147.

Tushman, M. L., Newman, W. H., \& Romanelli, E. (1986). Convergence and upheaval: Managing the unsteady pace of organizational evolution. California Management Review, XXIX(1), 29-44.

Zehir, C., \& Ozsahin, M. (2008). A field research on the relationship between strategic decision-making speed and innovation performance in the case of Turkish large-scale firms. Management Decision, 46(5), 709-724. 